\title{
Practical philosophy of education: the ecological-discursive paradigm as the complex problem
}

\author{
Halyna Baluta* \\ Kryvyi Rih State Pedagogical University, Department of Philosophy, 50086, Kryvyi Rih, Ukraine
}

\begin{abstract}
In the $21^{\text {st }}$ century, more attention is drawn to the development of ecological thinking. Instead of explicating treatment of nature, a human being should take care of it. Such a caring attitude should become an educational universal, so it is to be transmitted as value. However, the ecological-discursive paradigm is still problematic in education. Therefore, the objective of the paper is to analyze it as a complex approach in philosophy of education. The paper considers environmental anthropology as the methodological basis of the ecological-discursive paradigm. Ecological culture is analyzed as ethnics of conservation. The paper emphasizes that ecological thinking cannot be developed without changing an epistemological model. Thus, instead of facts and competences, the person's cognition should be based on values. The paper highlights the idea of diagnostic cognition, which is based on values. Its development in the process of education is the first step to the ecological-discursive paradigm.
\end{abstract}

\section{Introduction}

Philosophy of education is an area of contemporary practical philosophy that actively implements the "globalization parameter" because it takes into account the necessity to include ecological culture as a basic cultural form in the educational space. There is a question of what modern education should be, and it becomes an issue for consideration that takes into account the scenarios of global development. The progressive paradigms of education involved in the educational space are particularistic. Therefore, they are partially suitable for successfully overcoming the global crisis as "unpredictable obviousness". There are some reasons for that. Firstly, they remain essentially specialized and mostly based on science. Secondly, they are not intended for the formation of situational competencies, correlating with changeable parameters of the biosphere and anthropogenic consequences. Education remains beyond important educational values, which include readiness for life and understanding of the vital value of nature as "the home of being". The specialization, which is required for the development of civilized thinking, had a negative impact on the educated people's philosophical thinking and, as a result, on the development of institutions created to promote education. A. Whitehead, a classic of philosophy of education and one of its founders, admitted that the progress of science, which has caused a considerable separation of universities and to their autonomy, contributed to narrowing the breadth of thinking.

The thinker paid great attention to education as an indicator of intellectual progress. The philosopher writes: "As science grew, mind shrank in width of comprehension. The nineteenth century was a period of great achievement, suggestive of an anthill. It failed to produce men of learning with a sensitive appreciation of varieties of interest, of varieties of potentiality. It criticized and exploded, where it should have striven to understand" [1, p. 44]. Unfortunately, the well-described educational situation has not changed in the $21^{\text {st }}$ century. What does A. Whitehead mean when he speaks about understanding as a way of thinking and as an important criterion for the quality of education, educational value? He means the awareness of the meaning of education, which is the nature of our existence, the essential content of its depth [1, p. 44]. A. Whitehead motivates to draw more attention to understanding "if civilization is to survive" [1, p. 45].

A. Whitehead's philosophical methodology was defined by the principles of the unity of nature, the understanding of life as the ordered process, so a person must be inscribed in the general order of nature. This prompts the actualization of ethical, environmental, and communicative aspects of education, which reproduces the ethics of conservation, "ethics of intelligent transformations", as opposed to the unmanaged "ethics of pragmatic transformations". Therefore, the discursiveenvironmental approach can be suggested as an educational universal that highlights the ethics of the subjects' shared responsibility to save the environment and transform it wisely.

In the monograph "Social Ethics and Ecology. The dignity of human - respecting of nature", A. Yermolenko writes the following: "The Kantian question "what should I do?" is up-to-date, complemented by the question of what we should do together, how to substantiate our shared responsibility, in

\footnotetext{
* Corresponding author: moment71164@gmail.com
} 
which individual responsibility would be identified [2, p. 25]. The researcher emphasizes: "There has never been a question of responsibility for one's existence as a species because until now humankind has not been able to destroy itself as part of nature" [2, p. 182]. A. Yermolenko draws attention to the imperative of the present, formulated by Hans Jonas' ethics. He incorporated a metaphysical element into the dimension of ethical discourse. The ecological issues of "taking care of oneself" are the complex that catalyzes the change in the vector of social action, the value-based intentions of education on the basis of understanding morality as an important life-saving principle, and the intentions of what it means to be a human being or a person in the today's civilization.

\section{The principle of understanding}

The critique of the disadvantages of traditional educational culture, observed today, is reasonable since the traditional educational culture does not take into account the current social context and its challenges. Among the educational problems, the most topical issue is the gap between education and social dynamics, since the researchers do not consider the civilization sense of education. Neither personal success nor the social success of a certain country can be considered as real on the background of global challenges and constant environmental threats that are extremely unpredictable. The serious disadvantages are the fragmentation of knowledge, the lack of methodological bases that provide a picture of the unity of the world, and the "family affinity" of its phenomena. As mentioned above, the reproduction of the general picture is possible by introducing into the cognitive horizon the ethical "understanding" discourse, offered by Paulo Freire, Yuval Noah Harari, Dario Salas Sommer, Vladimir Lefebvre, Philip Zimbardo. They discussed the informational and methodological insufficiency of traditional education, which excludes the value of being, and minimizes reflective practices. Simultaneously, traditional education keeps the spirit of monologue in teaching, intellectual competition, and individual pragmatics. Moreover, traditional education does not take into account objective reality as a complex entity. It does not take into account the latest achievements of psychological, ethical and environmental studies.

For example, Dario Salas Sommer suggests the concept of "physics of morality", which is based on the idea of the universal order of being. He proves that nowadays "physics of morality" is a reliable tool for the practice of meaningful learning that takes into account the global perspectives: importance and inevitability of the global problems. Dario Salas Sommer greatly broadens the horizons of the stereotyped images of morality. He also discusses progressive features of modern education as practical philosophy through the lenses of anthropological pedagogy, focused on global thinking. He thinks that the study of "physics of morality" is very different from the usual intellectual and psychological techniques, based, as a rule, on mechanical repetition. D. Sommer thinks that we need to start with understanding ourselves and understanding our relationship with nature, for which we will proceed from several prerequisites. Some of them are based on quantum physics and allow proving in practice that every human action, depending on the moral qualities, in one way or another, influences the entire universe [3]. It is necessary to emphasize that the researcher brings up the theme of ontological or "noospheric" understanding of morality, in contrast to the academic interpretation of morality that regards it as the historically formed norm of social interaction, rooted in education, and as a sphere of autonomy, detached from nature. The researcher emphasizes that the notion of morality in our culture is limited and unrelated to the laws of nature [3]. True morality keeps witching the cosmic laws, expressed in the intention of understanding.

As we know, there are different interpretations of the concept of understanding. In the hermeneutic tradition, understanding is defined as the discovery of the meaning of a text, carried out in the process of interpretation. It is also viewed as the ontological principle, underlying the worldview. We are situated in being without the ability to embrace it as a whole. Therefore, knowledge of the world is preceded by cognitive instruction - preunderstanding, which sets the horizon of the process of cognition as interpretation. The change in epistemological perspective-tradition leads to a change in understanding/interpretation. The hermeneutical model of knowledge, passed through the lenses of tradition, has been taken into account by representatives of radical constructivism, justifying cognition as a tool of adaptation to the changeable living environment. The radical constructivism was developed by Humberto Maturana and Francisco Varela. Modern hermeneutics does not oppose understanding and interpretation since they tend to be regarded as complementary correlates.

In linguistic philosophy, the fundamental difference between interpretative schemes has been substantiated for different cultural types. Despite such a difference, "understanding" is treated as a universal platform of shared socio-cultural practices. This approach to understanding was developed by Carl Jung, Ludwig Wittgenstein, and Jürgen Habermas. In social science, Max Weber's approach is also taken into account. According to the scholar, understanding determines the meaning of social action and its value orientation. Nowadays, the idea of the social world as a construct of its agents acquires methodological value. It is considered by A. Schütz, P. Bourdieu, and A. Giddens. The social constructivism implies the real possibility of sociocultural transformations, caused by global challenges. Such challenges are viewed as the stable civilizational basis, independent of cultural forms and traditions. We define the value of life and its continuation as a common basis that removes linguistic and cultural barriers. It also unites personal interests and values with universal meaning. The diagnostics is considered to be a new meaning concerning the theme of understanding. It is treated as special knowledge, aimed at the timely detection of natural and social deformities and anomalies.

A. Whitehead asks: "What is understanding?" It is a self-evident thing, which has different parameters both in terms of magnitude and its structure. He writes: "In 
mathematics, as understood, the ideal fact stands out as self-evident" [1, p. 46]. The philosopher introduces the concept of "composition" to characterize the understanding as the basis of the methodological construct. The composition is defined in two ways: a) as the study of the system-forming factors that constitute a thing, its integrity, its obviousness; b) as the analysis of things as the unity of components, its effect on the environment. He emphasizes: "The first mode may be called the internal understanding, and the second mode is the external understanding" $[1$, p. 46]. In the first aspect, a thing is viewed as a result. In the second aspect, it is regarded as a causal factor. The sequence of fragments as self-evident details forms an argument that is consistent with understanding. A. Whitehead says that the sense of reasonableness and expediency is correlated with the growth of understanding. Using the achievements of science and philosophy, in particular, the anthropic principle, we can think of the natural state as the probable variety of natural laws, based on the idea of their unity and expediency, correlating the existing state with the value-intensive and transformative activities of a person, who is included in the natural horizon.

\section{Environmental pedagogical anthropology}

The formation of the environmental paradigm is associated with the names of A. Leopold, A. Schweitzer, G. Picht, E. Odum, H. Jonas, K. Lorenz, etc. The active mission of the leaders of the Club of Rome contributed greatly to the development of the environmental approach in philosophy. Such researchers as O. Höffe, D. Böhler, J. Passmore, M. Rock, L. Tribe, R. Spemann, A. Neugeisler, W. Frankena, K.-M. Meyer-Abich are representatives of environmental ethics in its variety of theories.

Despite the diversity of environmental approaches, communicative ethics is also an important approach, as it is the ethics of shared responsibility that actualizes the intersubjective philosophical paradigm. The conventional basis of environmental ethics was represented by J. Habermas, K.-O. Apel, M. Riedel, etc. J. Habermas considers that the discourse participants need to understand each other. Social action is possible through communicative action - a common understanding of the situation, its mutual adequate interpretation [4].

G. Picht was at the beginning of environmental anthropology as the doctrine of human essence. He considered a human being through the lenses of relation to nature. Moreover, the philosopher substantiated the principle of "human ecology" (Humanökologie), and predicted the connection between a human being and social institutions, believing that identity is contained not within a person, but outside personhood [2, p. 181].

It is necessary to mention that the anthropological turn in philosophy was determined by the contribution of M. Scheler, H. Plessner, A. Gehlen. It was caused by the attempt to eliminate the one-sided understanding of a human being as a purely spiritual being or a purely biological being. They promoted the principle of the holistic human being, who is a carrier of biological and cultural programmes. Furthermore, the holistic human being possesses a particular super-biological ability to enter the transcendental realm. Therefore, culture emerges as a "second" inalienable, humanized nature. Philosophical anthropology also played a great role in the formation of humanistic-oriented education, as philosophical anthropology contributed to the formation of the basic educational principles. M. Scheler and A. Gehlen defined and outlined the concept of "environment" (Umwelt). They understood it as the whole world. This definition was as opposed to the functional concept of "environment". According to the later, "every living creature has its environment related to its constitution" [2, p. 206]. The emphasis on reasonable spiritual parameters has somewhat replaced the natural foundation, so it can be regarded as secondary or self-evident nowadays. At the same time, the Christian and Renaissance understanding of nature was lost. That understanding treaded nature as spiritual creation - the perfect culture of the Creator himself when "unnatural" was understood as sinful, anti-good.

In Ukrainian tradition, the environmental theme in education is presented in the works of A. Yermolenko, I. Popova, S. Klepko, S. Kutsepal, T. Andryushchenko, and others. In this context, special attention should be paid to the research "Educational paradigm of ecological development of transformational society", conducted by I. Popova, in which introduction ecological ideas in educational space is considered as the main task of modernization of education in the $21^{\text {st }}$ century [5]. It should be noted that the researcher raised an important problem in educational culture. This fact can be considered as a good start on the way to the improvement of national education. In the research, we suggest enriching the educational content of the paradigm of environmentally friendly development with additional philosophical argumentation and methodology.

Therefore, to be a civilized person in the modern sense is to combine two ethical principles: concerning a human being and towards nature, guided by the ethics of concern for the world, its preservation. Environmental anthropology forms a new ethical image: human morality cannot be the result of mechanical subordination to social norms, but be based on autonomous reasoning and volition to pursue the highest transcendental values [3]. It should be noted that a considerable number of publications do not practically concern the educational practice in the aspect of specific steps towards the implementation of the unified type of educational standard, which would provide for a wide range of relevant competences. In particular, ecological competence would appear not as secondary among others, but as an educational fundamental value. Thus, environmental pedagogical anthropology must be treated as a theory and it should be concretized by a conceptual and methodological platform that implements the successful development of ecological culture and ecological thinking as higher-order thinking. 


\section{Ecological culture as the ethics of conservation}

At first glance, the elimination of the extremes of particular education seems possible due to the affirmation of the original relation "a human being nature - the universe" and due to the replacement of the value of education, which is in moral respect of nature of a person. However, it should be noted that in this case, the principles of environmental ethics do not appear as categorical, but only as hypothetical. They are implemented to some extent in the modern educational process, but they are not as effective as they should be. The general scientific scheme is preserved. It explains the universe from the lower to the higher, from nature to a human being as the intelligent but arbitrary master of the natural creation, who destroys the biological foundation. The scheme of explanation of the "higher through the lower" absolutizes the natural principles or the instincts that take sublimated or rationalized forms. Therefore, this scheme is also problematic, as the anthropological basis and the value sphere disappear. A human being with his system of values that humanize the world disappears from the spiritual horizon, remaining in the space of facts and instincts.

The unity, the synergy of a human being and nature can be understood through the lenses of "systems and synergy". Classical philosophical postulates lead to the following conclusion: everything that is in a person and consciousness, such as rationality or expediency is also inherent in nature, but in an implicit form. These postulates include Plato's, Socrates' and Newton's ideas. Plato wrote that the essence of being is to be implicated in causal action on other beings [6, p. 153]. Socrates believed that "a man is the microcosm in the macrocosm". According to Newton, "a book of nature written in the language of mathematics". Therefore, as A. Whitehead highlighted: "Physics abstracts from the element of soul, but due to that fact structural and mathematical relations (eternal objects) are part of the worldview" [7, p. 50].

The constant appeal to sensory perception as a source of knowledge has time delimited thinking from nature for a long. That idea has been expressed in Cartesian dualism. I. Kant considered the united world of phenomenal and noumenal. As A. Whitehead notes: "Mentality is an agent of simplification; and for this reason appearance is an incredibly simplified edition of reality" [6, p. 273]. The person's rationality as the permanent attribute is complemented by the moral criterion, which is powerful, but problematic from the standpoint of scientific proof. For a person as a natural being is the bearer of morality, can nature be moral if morality is regarded as the highest measure of expediency? Are there any correlations between a person's morality and nature's morality determined? Could it happen that the existence of a person and its consequences may appear to be inappropriate for the existence of nature?

Such hypothetical, unfinished model of worldview is important for the ethics of saving in its various modalities. In the process of forming an ecological culture, one can use "an appeal to the spirit". It means that a person does not create nature, but creates and saves it by appearing as the image of God. Moreover, there is also "an appeal to life". It means that a person is the bearer of life. Therefore, people save and continue it, as they are guided by the survival instinct. I. Mechnikov wrote about the survival instinct the following: "The survival instinct is undoubtedly developed in human beings. It is little expressed when they are born, but it is already sharply manifested in young children" [8, p. 94]. A. Schopenhauer, S. Kierkegaard, S. Freud discussed the unconscious force of "the fear of death". Finally, there is "an appeal to understanding". It is the presence of a fragile boundary, separating a person and nature, the real world and its appearance.

Therefore, there is a question of what directions and activity results should be included in the logic of scenarios development of a person and nature. The scenarios can be both ethical as well as anti-ethical, concerning arbitrary interference of a person in natural ties and relations. Paradoxically, the person's intrusion in natural processes is more threatening to a person than to nature. Nature with its hidden powerful potentialities has less impact on humankind.

\section{The epistemological pyramid and cognitive technologies}

Education is an important strategic resource that not only describes reality but also conserves, reproduces and transforms its contexts. Any problem, idea or phenomenon correlates with the system of knowledge, caused them, so the successful solution of a problem situation requires refinement, improvement or replacement of the previous system. Knowledge and its outcomes become socially and ethically oriented. The polyphony of philosophical discussions focused on the question of what knowledge and understanding are in its alternative forms, which establishes the relevance of hermeneutical discourse in pedagogical epistemology. In educational theory, there are noticeable transformations associated with the revision of educational priorities, focused on understanding cognition as an adaptive activity and knowledge itself as an "instrumental value", as opposed to knowledge as the sum of justified facts. In the history of philosophy, there were such epistemological models as contemplative, representative, hermeneutic, projective-constructive, etc. They generally characterized cognition as a kind of mental activity, rejecting its biological side. The representation of reality as the system of connections and relationships involving thinking is the product of evolutionary epistemology, which views knowledge as a way of adaption to the environment in the form of intellectual production. Therefore, cognition is regarded as a starting point, a function of universal evolution, and, what is more important, as an effective action that allows a living being to continue its existence in the environment.

The incorporation of thinking into the picture of reality creates the idea of thinking as an adaptation process - autopoiesis. H. Maturana and F. Varela treat the process of autopoiesis as the cognitive specificity of 
a person immersed in the environment of interaction with the environment as an expression of his or her ability to be an autonomous living system. However, this problem remains unsolved. The researchers admit that the biological mechanism tells us that operational stabilization in the dynamics of the body does not embody the way it is generated. Life leaves no imprint on its beginnings [9]. The shift of interaction to another mode pushes us out of the ordinary situation, and then we begin to think of the event as an observer, explaining it to those who did not notice, did not know or believed and so understood. The researchers say that the framework of such non-knowledge is the tradition within which knowledge functions. The tradition is a way not only to see and act but also a way to hide. Options for possible developments remain hidden until tradition and its scenarios become unfit for use, and that fact actualizes reflection. People and cultures are different, but their biological heritage is the same as a biological basis. Therefore, cognition may really belong to the biological realm, but in the realm of the spirit, it is always different, as it resides in one or another cultural tradition as a reflection - "following a general rule" on the principles of an awareness of the commonality of the living environment, taking into account the cognitive cultural diversity that is not inherent in contradict the "general rule" to conserve environment.

Thus, the research of cognition in evolutionary epistemology has formed a new understanding of human activity as determined by the tradition. Can the "diversification" tradition in education be based on moral and environmental bases? The epistemological pyramid of education based on facts, competences with values as its top can be rebuilt in the following way: values should be in the base of the pyramid, as they join facts, giving them an eco-conservation force, defining competencies; the meaning of the facts, and giving them the direction for development. I. Chernikova admits that incising risk is accompanied by adequate use of knowledge, which is the ability to think well [10]. R. Shenk's report at the $4^{\text {th }}$ International Conference on Cognitive Science outlined the suggestions for organizing the education system based on the achievements of cognitive science in understanding the nature of thinking. I. Chernikova outlines the following: "His program identifies 12 fundamental cognitive processes: modelling, experiment, prognosis, assessment, diagnosing, planning, causality, judgment, negotiation or negotiation skills, influence, teamwork, description. These principles should be taught to everyone as the basis for education, from early childhood, then at school and even at university [10, p. 107]. Among the basic skills description, planning and diagnosing are identified as the most important [10, p. 107]. Knowledge in its essence is increasingly becoming "diagnostic", as there is no field in which there is no need for timely diagnosis.

\section{Diagnostic cognition}

For the sake of environmental protection, health, selfimprovement, the ethics of conservation as a leading imperative of the global-discursive paradigm includes in the spectrum of educational procedures the idea of "caring for life", which is in line with the thinking of the diagnostic type. According to E. Krotkov and T. Nosova, diagnostics is not a doctrine, but a kind of cognitive activity that covers biological and social systems [11, p. 37]. The specificity of diagnostic is a combined intellectual skill associated with the formation of its cognitive images. Unlike other types of cognition, mostly aimed at evident facts, the diagnostic type of cognition encompasses the horizon of both evident and non-evident, which, in a methodological sense, corresponds to the substantiated picture of the world as the unity of reality and appearance. Diagnosing as a process of recognition always involves some obscurity or non-obviousness of the object, which may change the parameters or remain hidden in different situations or modes. An important component of diagnosing is also the process of identification, which means ascending from single facts to the general. The specificity of diagnosing also implies the presence of an a priori knowledge base, a database of the object of diagnosing, the presence of justified criteria, the construction of a cognitive image of the studying phenomenon by the mental transfer of noumenal features to the object of diagnosing [11, p. 48].

Therefore, diagnostic cognition is based on an understanding of the complex structure of reality - the presence in it of noumenal and phenomenal levels that explicitly show symptoms of the invisible. Furthermore, it requires complex thinking: logical culture, the culture of critical and philosophical thinking; consideration of contextual values, or, conversely, the ability to reduce context.

\section{The conclusion}

The diversity and unity of the world are not limited to the empirical sphere - the sphere of the visible. That was emphasized by I. Kant, A. Whitehead, R. Penrose, R. Grossman, and others. In particular, in the book "The Existence of the World: An Introduction to Ontology", R. Grossman emphasizes that the world is not limited to the physical universe. Philosophical ontology illuminates the structure "not so much of our real (actual) world, but any possible world whose existence is potentially permissible" [12, p. 101].

Timely diagnosis of environmental phenomena, analysis of their course and changes, comprehensive understanding of the possible consequences of intervention in the biosphere and designing strategies for their timely correction are valuable social skills and the result of effective civilized education. The above arguments outline the following:

- the need to change the epistemological tradition, which lies in the universal understanding of the systemic nature of reality, its ties and relationships, as opposed to fragmentary knowledge of the world and a person; - the prospect of incorporating the educational paradigm of eco-safety development into universal contexts of ecological-discursive educational theory and practice;

- directions of formation of ecological culture and ecological thinking as thinking of the highest order; - the actualization of eco-friendly ethical systems in educational and training practices; 
- reviewing the pyramidal structure of pedagogical epistemology as a unity of values, facts and competences, as opposed to facts, competences, and values;

- the use of cognitive technologies in educational processes as key intellectual procedures;

- the orientation of educational technologies to the ethics of conservation and diagnostic knowledge.

As H. Jonas wrote: "Any living being is an end in itself, which needs no further justification, and from this point of view man is no different from other living beings except that he may also have responsibility for them, that is, to care on the preservation of their purpose" [13, p. 152].

\section{References}

1. A. Whitehead, Modes of Thought (The Free Press, New York, 1968)

2. A. Yermolenko, Sotsialna etyka ta ekolohiia. Hidnist liudyny - shanuvannia pryrody (Social ethics and ecology. The dignity of human - respecting of nature). (Libra, Kyiv, 2010)

3. D.S. Sommer, Internal Ecology - Morals for XXI Century (Codex, Moscow, 2013)

4. J. Habermas, From the Pictures of the World to Life World (Idea-Press, Moscow, 2011)

5. I.V. Popova, Osvitnia paradyhma ekobezpechnoho rozvytku transformatsiinoho suspilstva (Educational paradigm of ecosafety development of transformational society). (The National Pedagogical Dragomanov University, Kyiv, 2016)

6. A. Whitehead, Adventures of Ideas, the 19th edn. (Cambridge University Press, London New York Toronto Bombay Calcutta, 1939)

7. A. Whitehead, Izbrannye raboty po filosofii (The selected works on philosophy). (Progress, Moscow, 1990)

8. I. Mechnikov, Etyudy o prirode cheloveka (Essays on human nature). (Medkniga, Kyiv, 2015)

9. H.R. Maturana, F.J. Varela, The Tree of Knowledge: The Biological Roots of Human Understanding (Shambhala Publications, Boston, 1992)

10. V.I. Chernikova, Epistemol. \& Philos. Sci. 27(1), 101 (2011)

11. Ye.A. Krotkov, T.V. Nosova, Epistemol. \& Philos. Sci. 10(4), 36 (2006)

12. Y.V. Shramko, Actual Probl. Mind. Philos. J. 18, 101 (2017)

13. H. Jonas, Pryntsyp vidpovidalnosti. U poshukakh etyky dlia tekhnolohichnoi tsyvilizatsii (The principle of responsibility. In search of ethics for technological civilization). (Libra, Kyiv, 2001) 